\title{
Effects of Light Treatment on Sleep, Cognition, Mood, and Behavior in Alzheimer's Disease: A Systematic Review
}

\author{
Micaela Mitolo ${ }^{a}$ Caterina Tonon ${ }^{a, b} \quad$ Chiara La Morgia ${ }^{c, d} \quad$ Claudia Testa $^{e}$ \\ Valerio Carellic, d Raffaele Lodi ${ }^{a, b}$ \\ a Department of Biomedical and NeuroMotor Sciences, Functional MR Unit, University of \\ Bologna, Bologna, Italy; ${ }^{b}$ IRCCS Istituto delle Scienze Neurologiche di Bologna, Diagnostica \\ Funzionale Neuroradiologica, Bologna, Italy; ${ }^{C}$ Department of Biomedical and NeuroMotor \\ Sciences, University of Bologna, Bologna, Italy; ${ }^{d}$ IRCCS Istituto delle Scienze Neurologiche \\ di Bologna, Clinica Neurologica, Bologna, Italy; e Department of Physics and Astronomy, \\ University of Bologna, Bologna, Italy
}

\section{Keywords}

Alzheimer's disease $\cdot$ Bright light treatment $\cdot$ Sleep $\cdot$ Cognition $\cdot$ Behavior

\begin{abstract}
Background: Bright light treatment is a therapeutic intervention mainly used to treat sleep and circadian disturbances in Alzheimer's disease (AD) patients. Recently, a handful of studies also focused on the effect on cognition and behavior. Conflicting findings are reported in the literature, and no definite conclusions have been drawn about its specific therapeutic effect. Summary: The aim of this review is to provide a critical evaluation of available evidence in this field, highlighting the specific characteristics of effective bright light treatment. Eligible studies were required to assess at least one of the following outcome measures: sleep, cognition, mood, and/or behavior (e.g., depression, agitation). A total of 32 articles were included in this systematic review and identified as research intervention studies about light treatment in AD. The quality of the papers was evaluated based on the US Preventive Service Task Force guidelines. Key Messages: Overall, the current literature suggests that the effects of light treatment in AD patients are mixed and may be influenced by several factors, but with a general trend toward a positive effect. Bright light seems to be a promising intervention treatment without significant adverse effects; therefore, further well-designed randomized controlled trials are needed taking into account the highlighted recommendations.
\end{abstract}


Mitolo et al.: Effects of Light Treatment in Patients with Alzheimer's Disease

\section{Introduction}

Alzheimer's disease (AD) is the most frequent cause of dementia in the elderly [1] and AD patients may present with sleep disturbances and dysfunction of circadian rhythms [2]. These abnormalities might also occur in normal aging, although they are more frequent and pronounced in older adults with dementia [3]. Various forms of dementia, such as vascular dementia or dementia with Lewy bodies, are associated with different types of sleep and circadian disturbances. In AD, 44\% of patients are affected by a sleep disorder and, differently from other forms of neurodegenerative disorders, the prevalence and severity of this disturbance increase with AD severity [3]. Previous studies highlighted a bidirectional relationship between $\mathrm{AD}$ pathology, especially amyloid- $\beta$ plaque accumulation, and sleep disturbances [4]. The neurobiological bases of circadian disturbances were previously related to neuronal loss in the suprachiasmatic nucleus (SCN) $[5,6]$.

Postmortem studies in $\mathrm{AD}$, besides the well-known neurodegenerative features of the brain, also highlighted retinal and optic nerve tissue pathology [7, 8]. In particular, histological studies reported degeneration of the inner retina with loss of retinal ganglion cells (RGCs) and depletion of related axons in the optic nerve [7, 9]. These findings were more recently confirmed in cohorts of patients studied in vivo with optical coherence tomography showing a thinning of the retinal nerve fiber layer thickness [10-13]. The specific vulnerability of the inner retina to AD pathology is further supported by the finding of $\beta$-amyloid deposits in the retina of AD patients [14-16], recently demonstrated also in vivo in AD patients [17]. Moreover, La Morgia et al. [18] showed that these $\beta$-amyloid deposits are evident within and around a specific subpopulation of RGCs, the melanopsin RGCs (mRGCs) that represent 1-2\% of all RGCs. The loss of these cells was evident even with a normal RGC count, supporting a specific AD pathology affecting mRGCs. The mRGCs, by expressing the photopigment melanopsin, are intrinsically photosensitive and operate as the photoreceptors entraining circadian rhythms to light/dark cycles $[19,20]$. Ambient light information is, in fact, sent to the brain by mRGCs through the retinohypothalamic tract, projecting to the SCN of the hypothalamus $[21,22]$. When compared to age-matched controls, AD patients had a greater loss of mRGCs, and the remaining mRGCs exhibited a decreased dendritic diameter and abnormal morphology, suggesting functional impairment of the surviving cells in their ability to fully transmit the light information from the retina to $\operatorname{SCN}[18,23,24]$.

Considering the key role of mRGCs on circadian rhythms and sleep, these cells are particularly relevant to be potentially exploited for therapeutic options using light. Besides the reduced sensitivity to the effect of light on the central nervous system, AD patients also experience a reduction in general sensory input and less exposure to bright environmental light. These aspects may also have an impact on patient's mood and cognition, contributing to the development of behavioral disturbances, depression, and general cognitive dysfunction [2527].

Since the early 1990s, several researchers have examined the effectiveness of bright light therapy (BLT) in dementia patients. The majority of these studies focused on the effects of light on sleep and circadian rhythms. However, a handful of researchers also studied the effects on cognition, mood, and behavior. Due to the heterogeneity of light treatment (e.g., type of intervention, duration, light intensity) and the heterogeneity of the studied populations (e.g., underlying diagnosis, stage of disease, sample sizes), conflicting findings have been reported [28-31].

The aim of this systematic review is to describe the current state of knowledge in this field, exploring the effect of light treatment on sleep, cognition, mood, and behavior in AD. The specific characteristics of successful treatments will be described in detail, providing recommendations for future research. 


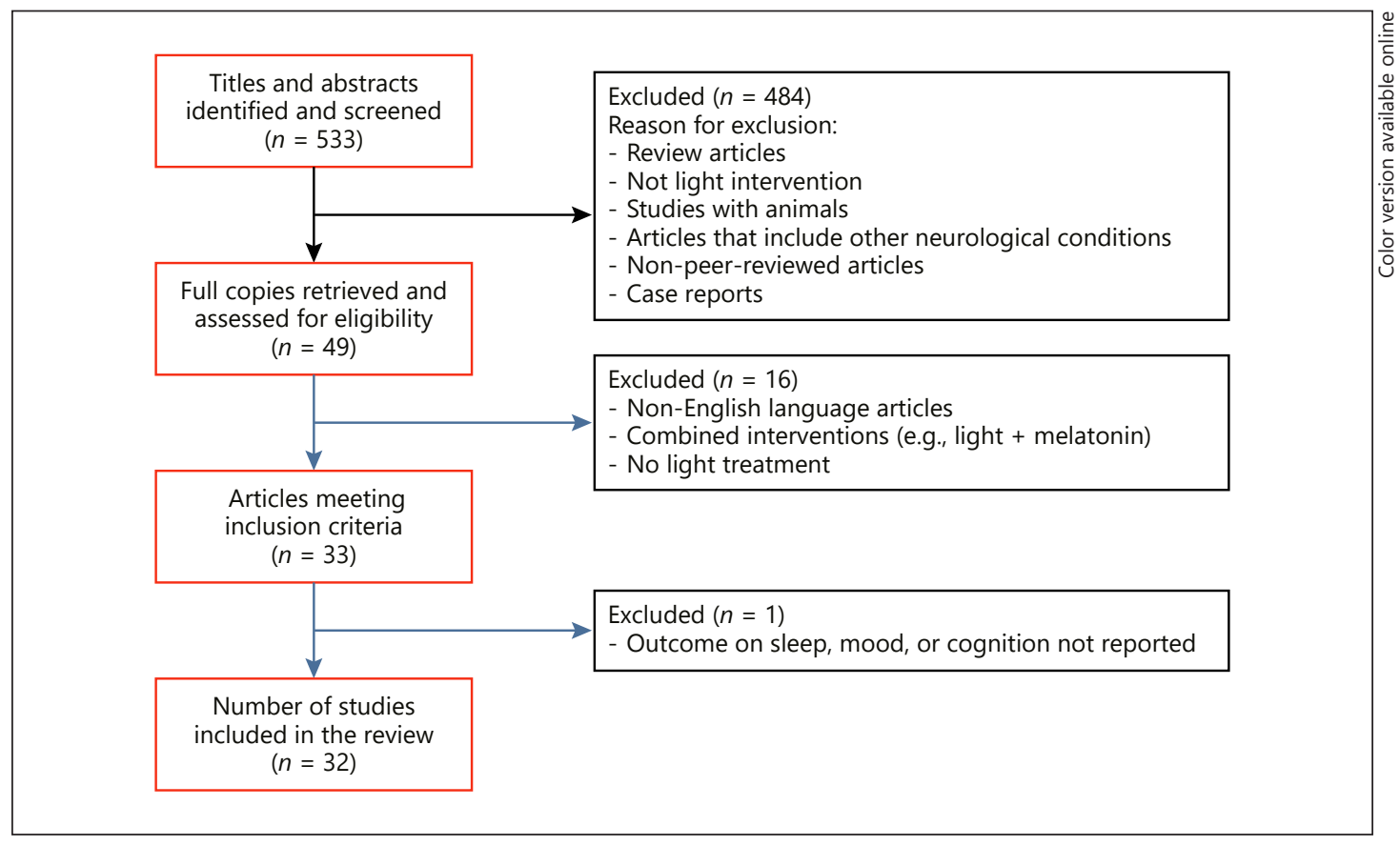

Fig. 1. Flow chart of the study selection process.

\section{Methods}

\section{Search Strategy}

The objectives and search strategy were established using the Population, Intervention, Comparator, Outcome (PICO) scheme [32]. An online literature search of PubMed and Web of Science using the terms ("light treatment" OR "light therapy" OR "bright light") AND ("Alzheimer" OR "Dementia") AND ("cognition" OR "memory" OR "attention" OR "sleep" OR "circadian rhythms" OR "mood" OR "depression" OR "agitation") was undertaken for all articles published until May 2017 (see Appendix). Using the reference lists of the retrieved articles, additional papers were identified. Previous systematic reviews on this topic and references from the review papers were also examined.

\section{Inclusion/Exclusion Criteria}

Eligible studies were required to assess at least one of the following outcome measures: sleep, cognition, mood, and/or behavior (e.g., depression, agitation). The abstracts or complete reports were reviewed to exclude articles according to the following exclusion criteria: (1) not light intervention, (2) review articles, (3) studies that included patients with other neurological conditions, (4) animal studies, (5) non-peerreviewed articles, (6) non-English language articles, (7) case reports. A total of 32 articles were fully analyzed with the aim of characterizing the specificity and duration of the light interventions, the disease severity, and all those factors that could influence the outcome measures. The included articles were published between 1992 and 2017.

\section{Quality Assessment}

The quality of the scientific evidence provided by these articles was classified, and an overall recommendation for the efficacy of this intervention was provided based on the US Preventive Service Task Force guidelines [33]: Level I, Evidence obtained from properly designed randomized controlled trial; Level II-1, Evidence obtained from well-designed controlled trials without randomization; Level II-2, Evidence obtained from well-designed cohort or case-control analytical studies, preferably from more than one center or research group; Level II-3, Evidence obtained from multiple time series studies with or without the intervention; Level III, Opinions of respected authorities, based on clinical experience, descriptive studies, or reports of expert committees (Table 1). 
Dementia

Cognitive Disorders \begin{tabular}{l|l}
\hline Dement Geriatr Cogn Disord 2018;46:371-384 \\
\hline DOI: 10.1159/000494921 & $\begin{array}{l}\text { c 2018 S. Karger AG, Basel } \\
\text { www.karger.com/dem }\end{array}$ \\
\hline
\end{tabular}

Mitolo et al.: Effects of Light Treatment in Patients with Alzheimer's Disease

\section{Results}

Identification and Selection of Studies

The literature search process is described in Figure 1. Overall, we reviewed 533 studies, including overlapping search results from different databases. A total of 484 publications were excluded according to the defined exclusion criteria, and a total of 49 papers were retrieved and assessed for eligibility. On initial evaluation, 16 articles were excluded because they included combined interventions (e.g., light therapy and melatonin) or were not written in English. A closer analysis of the remaining 33 full articles showed that one of them did not report any outcome measure, and therefore it was excluded. A total of 32 articles were included in this review and identified as research intervention studies of light treatment in AD. Sleep, circadian rhythms, cognition, mood, and behavior were used as outcome measures. Detailed information is given in Table 1 and described below.

\section{Effect on Sleep and Circadian Rhythms}

In total, 25 studies examined the effect of light treatment on sleep and circadian rhythms, and most of these used actigraphic measurements, specifically Interdaily stability (IS), Intradaily variability (IV), and Relative amplitude (RA), as outcome measures.

Although there was significant heterogeneity in the type of light treatment, duration of each intervention, and time of light exposure, most of these studies reported beneficial effects.

Ancoli-Israel et al. [34] compared bright light during morning versus bright light during evening and dim light during morning for 10 days. They found a lengthening of the maximum sleep bouts during night only in the first two conditions, highlighting that both morning and evening bright light resulted in more consolidated sleep at night [34]. Furthermore, in another study, the same authors showed that increasing exposure to morning bright light delayed the acrophase of the activity rhythm and made the circadian rhythms more robust [35].

Figueiro et al. [36, 37] also obtained an improvement in sleep parameters (e.g., increased total sleep time and sleep efficiency) using a tailored lighting intervention with bright light, from 6 or 8 am to $6 \mathrm{pm}$, in a group of patients diagnosed with AD and related dementia; however, these authors did not show any effect on the IS and IV parameters. Similar results were also found by Sloane et al. [38] who, after a tailored lighting intervention, did not find any significant changes in the actigraph measures (i.e., IS and IV scores); light stimulation levels achieved in this study seem to have some effect on sleep pattern, albeit minor and not statistically significant.

Differently, van Someren et al. [39] demonstrated that patients with AD and related dementia, after 4 weeks of bright light intervention, showed increased IS, which quantifies the synchronization to the 24-h light-dark cycle, and decreased IV, indicating a decreased rhythm fragmentation. These improvements indicate a more stable organization of the circadian rest-activity rhythm; however, no significant changes were found in the amplitude of the rhythm. Rest-activity recordings were also reported by Fontana Gasio et al. [40] who showed no significant changes of circadian stability or amplitude characteristics of the restactivity cycle (i.e., IS, IV, RA); however, the dawn-dusk simulation group tended to have shortened "sleep latency," longer "sleep duration," more nocturnal immobility, and less nocturnal activity than the dim red control group. The average intensity of daytime light received by these patients was low ( $<300$ lux, and usually much lower); therefore, probably not sufficient to produce measurable actigraphic changes.

Fetveit et al. [41, 42] demonstrated that morning bright light treatment administered for 2 weeks clearly improved sleep efficiency (from 73 to 86\%), reducing also daytime sleep and waking time within nocturnal sleep by nearly $2 \mathrm{~h}$. Interestingly, the authors showed that sleep efficiency remained significantly higher than the pretreatment 4 weeks after treatment termi- 
Dementia

and Geriatric
Cognitive Disorders
Dement Geriatr Cogn Disord 2018;46:371-384

DOI: 10.1159/000494921

2018 S. Karger AG, Base

Mitolo et al.: Effects of Light Treatment in Patients with Alzheimer's Disease

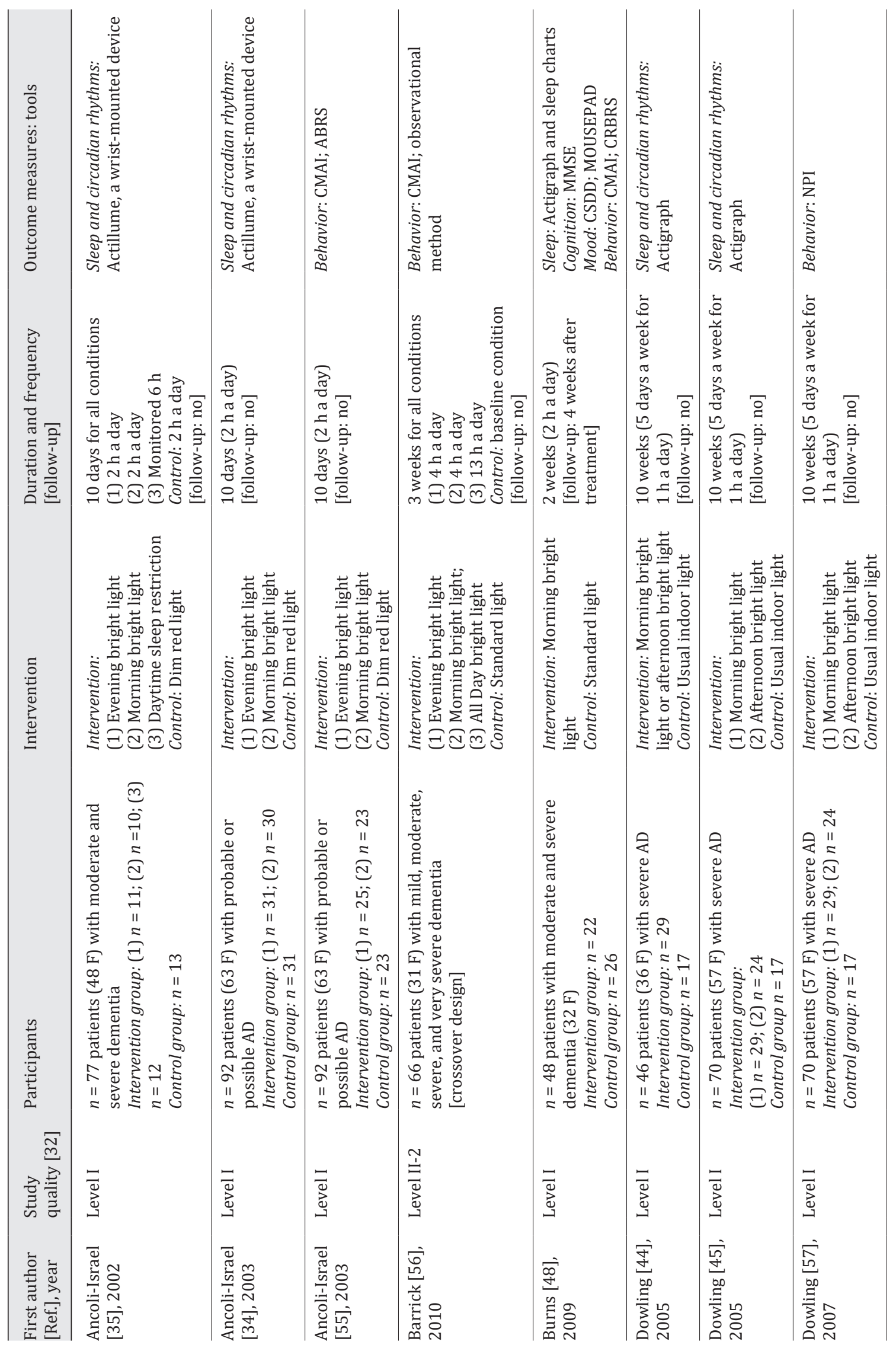




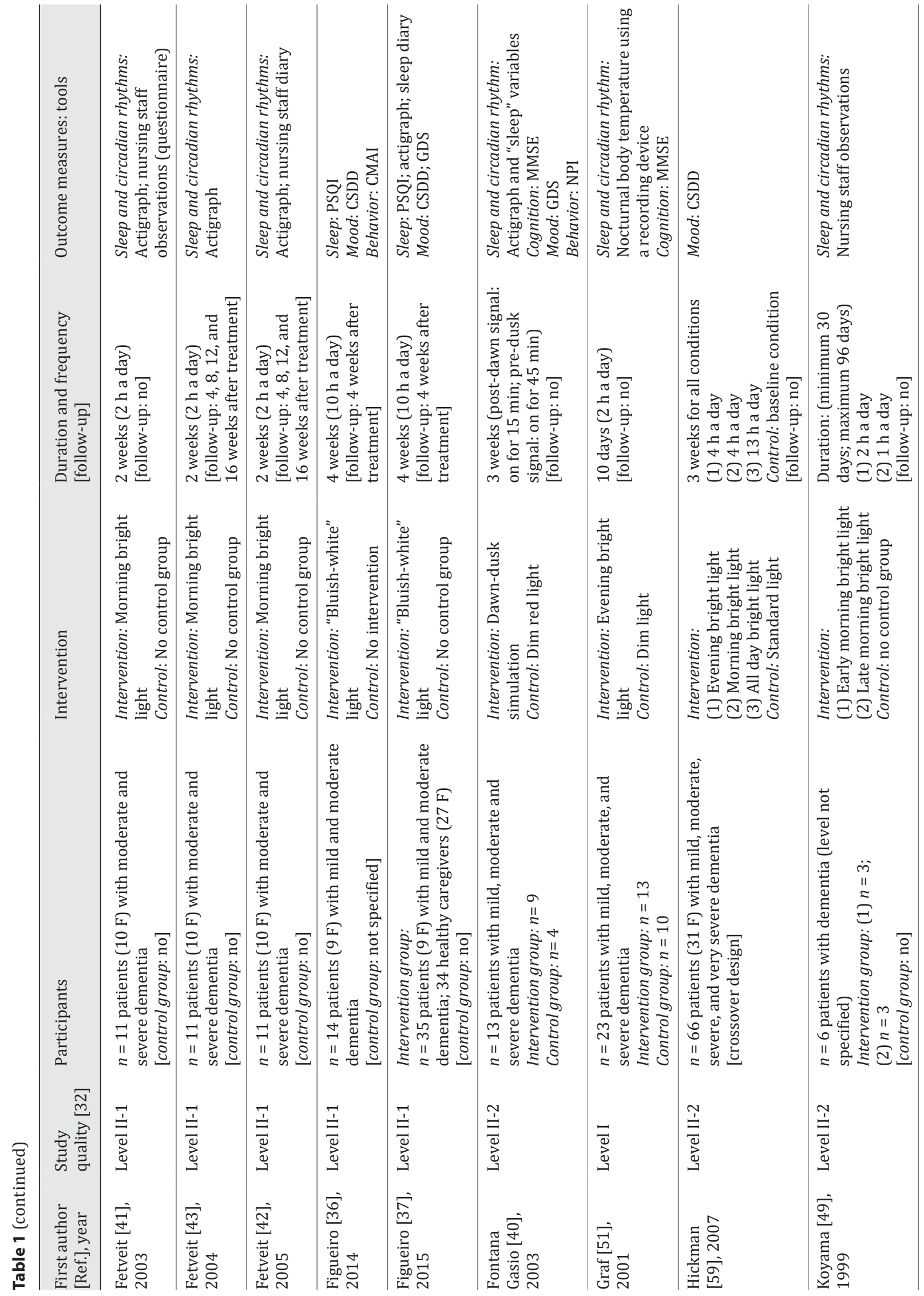


Dementia

and Geriatric
Cognitive Disorders
Dement Geriatr Cogn Disord 2018;46:371-384

DOI: 10.1159/000494921

(c) 2018 S. Karger AG, Base

Mitolo et al.: Effects of Light Treatment in Patients with Alzheimer's Disease

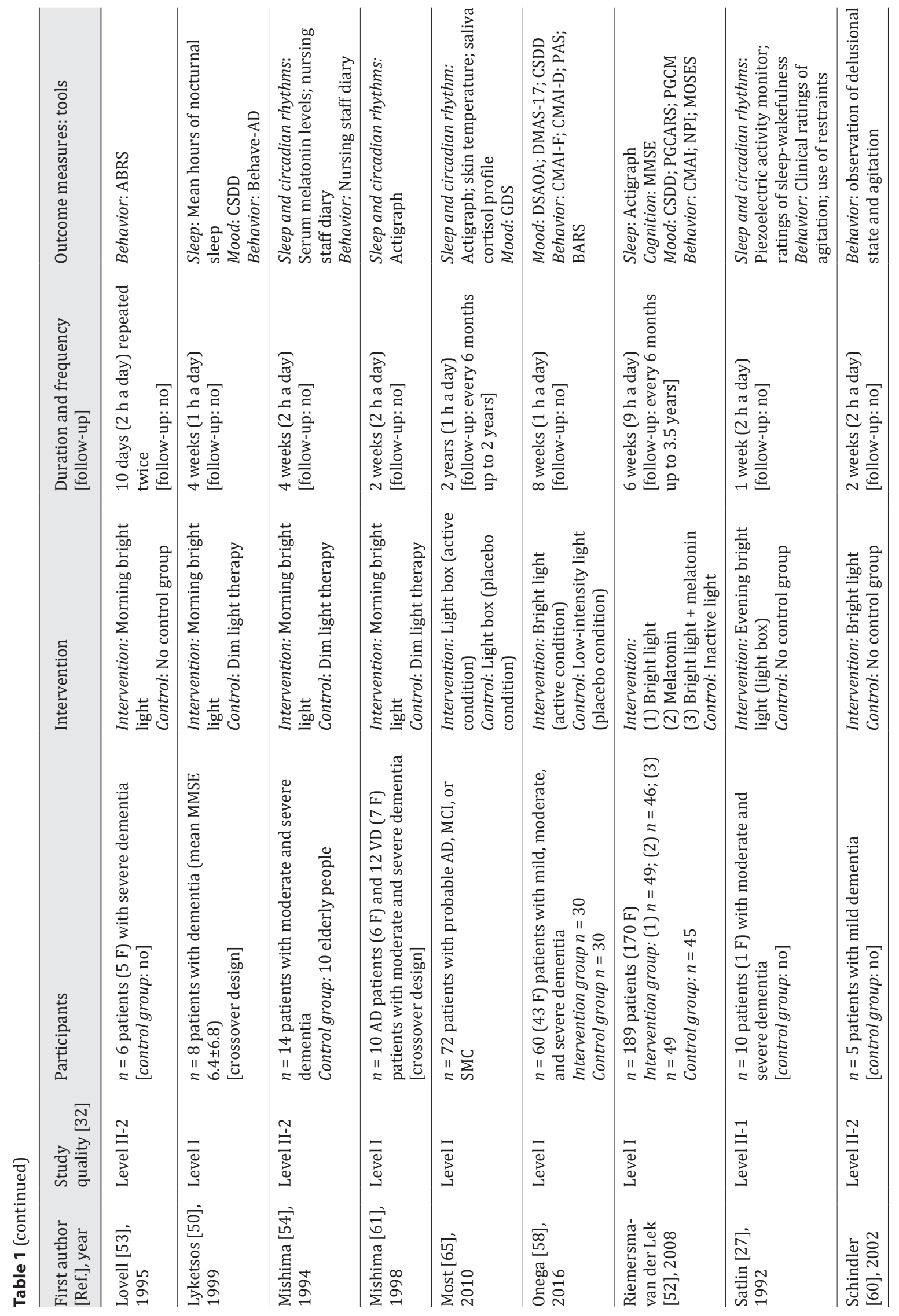


Dementia

and Geriatric
Cognitive Disorders
Dement Geriatr Cogn Disord 2018;46:371-384

378

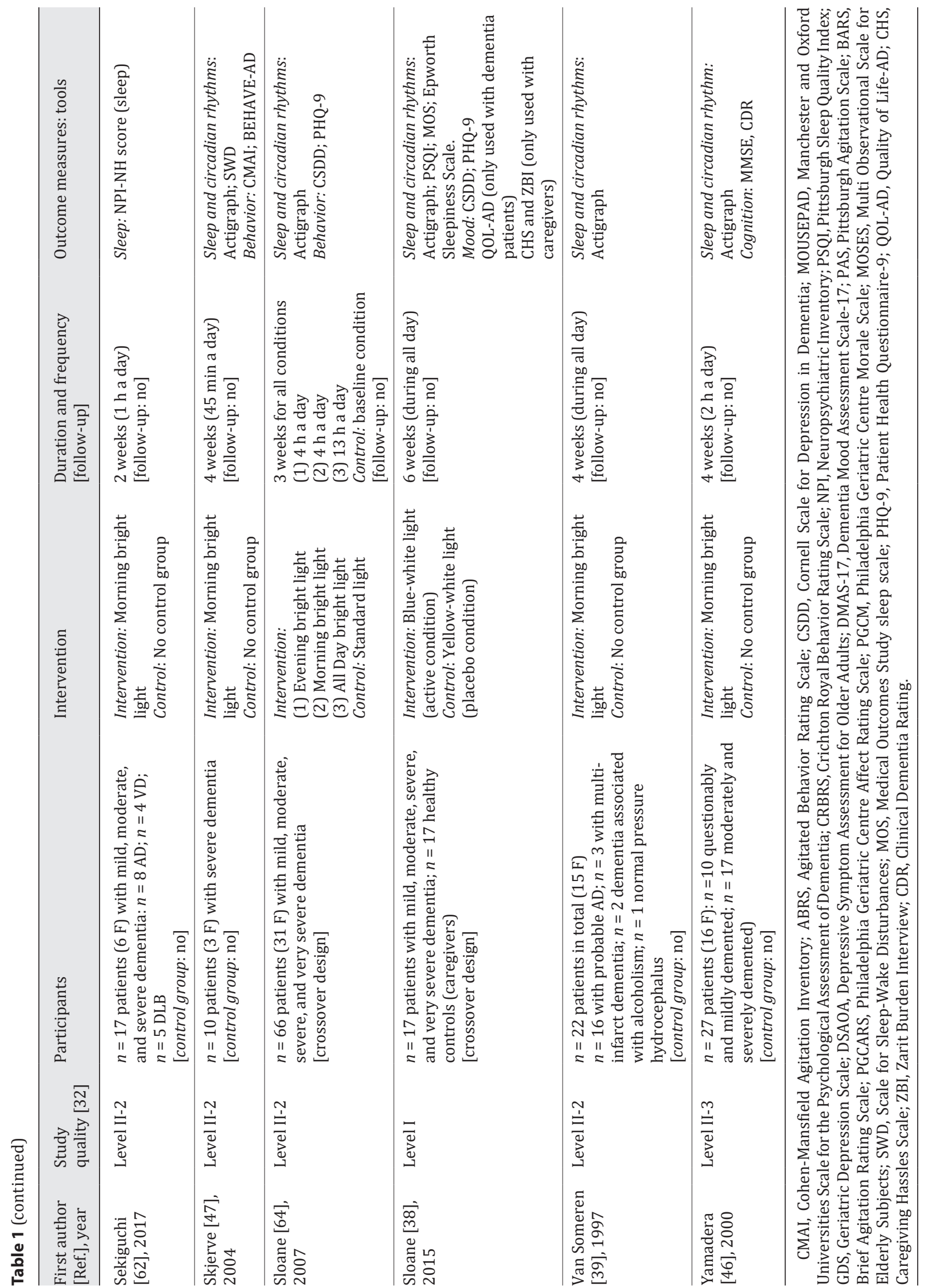


Mitolo et al.: Effects of Light Treatment in Patients with Alzheimer's Disease

nation, and sleep onset latency was significantly reduced up until 12 weeks posttreatment [43].

Conflicting findings were described by Dowling et al. [44, 45] demonstrating that $1 \mathrm{~h}$ of bright light, administered to institutionalized subjects with AD (mean age 84 years) for 10 weeks either in the morning or afternoon, did not lead to overall improvement in measures of sleep-wake and rest-activity compared to a control group that received usual indoor light. Only a trend toward significance in amplitude and in the rest-activity acrophase with improvement in the experimental group and worsening in the control group was found. However, no significant differences were found in variables derived from the nonparametric circadian rhythm analyses (i.e., IS, IV, or RA). According to the authors, the possible explanation for the lack of efficacy of this treatment is the old age of all participants and the severity of dementia (mean Mini-Mental State Examination [MMSE] score $=7$ ). Subjects respond to light differently across the lifespan, and the severity of dementia may have also led to a weak sensitivity to the light exposure [46].

Furthermore, also Skjerve et al. [47] did not find significant differences on the variables IS, IV, or RA after a short bright light treatment; in this study, the authors concluded that the short treatment period (i.e., 4 weeks) was not sufficient to influence the circadian rhythm in severely demented patients. Another possible relevant factor influencing the response to light treatment is the season of the year. Burns et al. [48], applying bright light from 10 am to $12 \mathrm{pm}$ in a group of people with dementia, found beneficial effects on sleep, which were more marked during winter than during summer. Specifically, they suggest that light must be turned on not earlier than the autumn equinox, when the external light cues are compromised, and turned off not later than the spring equinox.

Overall, previous findings suggest that the effects of light treatment on sleep and circadian rhythms in people with dementia are mixed and may be influenced by several factors, but with a general trend toward a positive effect of light therapy on sleep [49, 50]. Since light treatment does not have significant adverse effects, the development of studies with bigger samples and longer follow-up periods is warranted in order to generalize these results and verify whether the effects on sleep persist over time.

\section{Effect on Cognition}

The effect of light treatment on cognition was evaluated in 5 studies. Burns et al. [48] compared standard fluorescent tube light with morning bright light treatment. Fontana Gasio et al. [40] compared dawn-dusk simulation with "placebo" dim red light. Graf et al. [51] compared evening bright light with dim light. Yamadera et al. [46] explored the effects of BLT in a group of Alzheimer-type dementia patients. Finally, Riemersma-van der Lek et al. [52] compared all day bright light with dim light and monitored their patients up to 3.5 years. All these studies found modest positive effects on cognition, and one of them also showed that these improvements were maintained over time [52]. However, these studies presented the limitation that the only outcome measure used to monitor patients' cognitive status was the MMSE, a basic, and relatively insensitive screening test. Further studies with a more extensive range of cognitive tests and aimed to explore different cognitive abilities are needed to confirm these preliminary results and to define the specificity of these improvements.

\section{Effect on Mood and Behavior}

In total, 19 studies explored the effect of light treatment on mood and/or behavior disorders (e.g., depression, agitation, aggression). Some of these studies showed that, in people with dementia, BLT might have some effect on reducing agitation [48, 53, 54]; this behavior improvement is more marked in winter when the external light cues are compro- 
mised [48]. As for the effects on sleep, also the severity of the disease might have an influence on the light treatment effects.

Ancoli-Israel et al. [55] showed that, in a group of severe AD patients, morning bright light delayed the acrophase of the agitation rhythm by over $1.5 \mathrm{~h}$, but the overall agitation was not ameliorated. Since the SCN of patients with severe AD is likely to be more degenerated, and the circadian activity rhythms deteriorate as the disease progresses, it is still possible that patients with mild or moderate AD would benefit from light treatment more than those with severe AD. For example, Figueiro et al. [37] treated a group of 35 patients with mild or moderate dementia for 4 weeks with a tailored lighting intervention and, differently from previous studies, they showed a significant reduction of depressive symptoms. Barrick et al. [56] showed that ambient bright light is not effective in reducing agitation in institutionalized persons with dementia and may exacerbate this behavioral symptom in severely demented patients. Another study that described a light treatment in nursing home residents with AD showed small changes in neuropsychiatric behaviors (e.g., aggression, depression, eating disorders); however, the authors concluded that the magnitude of these changes do not represent clinically significant findings [57]. Onega et al. [58] showed that bright light exposure was associated with significant improvement in depression and agitation, while participants receiving low-intensity light displayed no significant changes or higher levels of depression and agitation. Their findings support the use of bright light exposure to reduce depression and agitation in dementia patients. Other authors showed that BLT is beneficial in some patients with dementia by decreasing depressive or agitation symptoms but may worsen symptoms in others [59,60]. The negative effects for some participants and all these conflicting findings suggest that highintensity ambient lighting should be tailored on an individual basis taking into account different variables.

\section{Discussion}

BLT is a therapeutic intervention mainly used to treat sleep and circadian disturbances in $\mathrm{AD}$ patients. Recently, a handful of studies also focused on the effect of BLT on improving cognition and reducing depression and agitational behavior in patients with dementia. However, conflicting findings have been reported in the literature, and no definite conclusions have been drawn about its specific therapeutic effect. This systematic review aimed at describing the status of the field and shedding light on the specific characteristics of successful bright light treatments.

The heterogeneity of disease severity and the age of participants seem to have an influence on the light treatment effects $[44,45]$. Patients with mild to moderate AD, with more intact SCNs, showed greater response to light in comparison to patients with severe AD [46]. Other studies in severely demented patients showed that ambient bright light, instead of inducing improvements, might sometimes exacerbate their behavioral symptoms [56]. Bright light effects could vary with the severity of the disease but also with the type of dementia; Mishima et al. [61] showed a significant improvement after BLT in patients with vascular dementia, but not in patients with AD. More recently, also Sekiguchi et al. [62] showed different results in different dementia patients, suggesting that BLT is more effective in patients with mildmoderate AD. Considering this body of evidence, we suggest that mild and moderate AD patients might benefit more from BLT than patients with severe dementia. One of the limitations of the current literature in this field is the absence of an accurate dementia diagnosis and clinical characterization in the majority of the studies. Moreover, most of the studies analyzing the effects of BLT in AD patients included cases based only on a clinical diagnosis 
of AD without any supportive diagnostic criteria (e.g., CSF or PET-amyloid) [63], and this might represent a potential confounding factor.

Furthermore, day length is a powerful factor in influencing seasonal and daily activity and circadian rhythms. In fact, successful BLT studies showed more marked beneficial effects during winter, when the external light cues are compromised, than during summer [48, 37]. Therefore, it is suggested that to obtain more beneficial effects, light must be turned on no earlier than the autumn equinox, and turned off not later than the spring equinox [48]. To minimize the potential bias from differences in daylight exposure, some authors recommended equally distributing treatment and placebo conditions across seasons [56, 64]. Another relevant aspect is the setting in which the light intervention is delivered and the modality of light exposure. Patients living at home may still be mobile and can have activities outside the house, while those living in nursing homes have fewer opportunities to spend time outdoors. Therefore, a lighting intervention in a more controlled environment, such as nursing homes, will give the opportunity to receive the lighting intervention in a homogenously lighted and controlled environment and therefore may be more effective than the same intervention at home [37].

Regarding the type of light exposure, previous studies showed mood and behavior improvement (e.g., reduced agitation) using "light boxes" [65, 27]. Often, in these cases research staff attended the intervention, actively keeping the participants seated in front of the light. These social exchanges could have independently improved study participant agitation [56]. Therefore, other modalities of light treatment, which provide target exposure levels without adding a potentially confounding staff effect, may represents a more valid method to explore the effects of bright light treatments. Moreover, most of the studies used white bright light sources without controlling for wavelength. Given that AD patients when compared to agematched control have a greater loss of mRGCs and these cells are particularly sensitive to monochromatic blue light (at $470 \mathrm{~nm}$ ) [66], the use of more selective wavelength would be more appropriate in tailoring light effectiveness on sleep and cognition in these patients.

Further, it should be highlighted that the nonsignificant results reported in some studies may be due to small sample sizes and to the heterogeneity of patient groups, leading to insufficient power for detecting differences; randomized control trials with larger samples are needed to confirm these preliminary results. In addition to all of the above recommendations, a wider range of outcome measures including brain structural and functional changes and extensive cognitive assessments are also needed to better define the specificity of light treatment effects. Moreover, since many of these patients are also experiencing age-related eye diseases including glaucoma, the exclusion of ocular pathologies with a complete neurophthalmological evaluation possibly interfering with light treatment must be considered. Finally, none of the studies measured in a quantitative way the ambient and outdoor light exposure using appropriate light sensors, and this might represent a possible confounding factor in evaluating the effectiveness of BLT.

BLT has also been considered one of the first-line treatments for seasonal affective disorder, yet a growing body of literature supports its use in other neuropsychiatric conditions including nonseasonal depression [67]. However, unlike administering BLT as monotherapy, studies that administered BLT as adjunct to antidepressant medications have failed to find evidence of efficacy [68]. Although still questionable in nonseasonal types of depression, many studies have reported it to be an effective treatment option for bipolar depression [67]. BLT seems to be effective also in improving both disordered-eating behavior and mood acutely, although the timing of symptom response and the duration of treatment effects remain unclear [69].

Overall, bright light seems to be a promising intervention treatment, and it does not have significant adverse effects; therefore, further well-designed randomized controlled trials are needed, and all of the above recommendations should be taken into account when designing appropriate interventions for ameliorating sleep and circadian rhythms in AD. 


\section{Statement of Ethics}

The authors have no ethical conflicts to disclose.

\section{Disclosure Statement}

The authors have no conflicts of interest to declare.

\section{Funding Sources}

This work was supported by the Italian Ministry of Health (GR-2013-02358026).

\section{Appendix}

Search Strategy

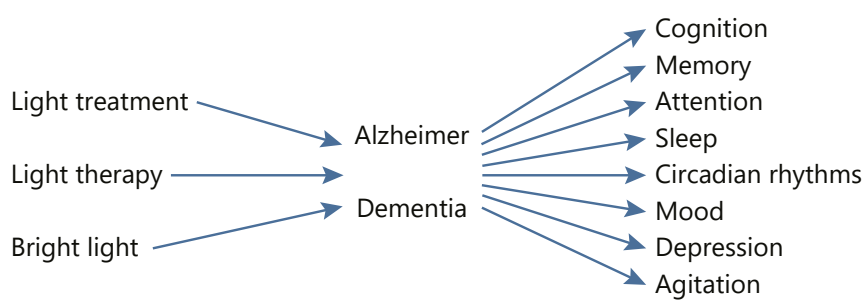

\section{References}

1 Hickman RA, Faustin A, Wisniewski T. Alzheimer disease and its growing epidemic: risk factors, biomarkers, and the urgent need for therapeutics. Neurol Clin. 2016 Nov;34(4):941-53.

2 Peter-Derex L, Yammine P, Bastuji H, Croisile B. Sleep and Alzheimer's disease. Sleep Med Rev. 2015 Feb;19: 29-38.

3 McCurry SM, Reynolds CF 3rd, Ancoli-Israel S, Teri L, Vitiello MV. Treatment of sleep disturbance in Alzheimer's disease. Sleep Med Rev. 2000 Dec;4(6):603-28.

4 Ju YE, Lucey BP, Holtzman DM. Sleep and Alzheimer disease pathology-a bidirectional relationship. Nat Rev Neurol. 2014 Feb;10(2):115-9.

5 Liu RY, Zhou JN, Hoogendijk WJ, van Heerikhuize J, Kamphorst W, Unmehopa UA, et al. Decreased vasopressin gene expression in the biological clock of Alzheimer disease patients with and without depression. J Neuropathol Exp Neurol. 2000 Apr;59(4):314-22.

6 Stopa EG, Volicer L, Kuo-Leblanc V, Harper D, Lathi D, Tate B, et al. Pathologic evaluation of the human suprachiasmatic nucleus in severe dementia. J Neuropathol Exp Neurol. 1999 Jan;58(1):29-39.

7 Blanks JC, Hinton DR, Sadun AA, Miller CA. Retinal ganglion cell degeneration in Alzheimer's disease. Brain Res. 1989 Nov;501(2):364-72.

8 Sadun AA, Bassi CJ. Optic nerve damage in Alzheimer's disease. Ophthalmology. 1990 Jan;97(1):9-17.

9 Hinton DR, Sadun AA, Blanks JC, Miller CA. Optic-nerve degeneration in Alzheimer's disease. N Engl J Med. 1986 Aug;315(8):485-7.

10 Coppola G, Di Renzo A, Ziccardi L, Martelli F, Fadda A, Manni G, et al: Optical Coherence Tomography in Alzheimer's Disease: A Meta-Analysis. PLoS One. 2015 Aug;10(8):e0134750.

11 den Haan J, Verbraak FD, Visser PJ, Bouwman FH. Retinal thickness in Alzheimer's disease: A systematic review and meta-analysis. Alzheimers Dement (Amst). 2017 Jan;6:162-70.

12 Kirbas S, Turkyilmaz K, Anlar O, Tufekci A, Durmus M. Retinal nerve fiber layer thickness in patients with Alzheimer disease. J Neuroophthalmol. 2013 Mar;33(1):58-61.

13 Paquet C, Boissonnot M, Roger F, Dighiero P, Gil R, Hugon J. Abnormal retinal thickness in patients with mild cognitive impairment and Alzheimer's disease. Neurosci Lett. 2007 Jun;420(2):97-9.

14 Cotman SL, Halfter W, Cole GJ. Agrin binds to $\beta$-amyloid (Abeta), accelerates abeta fibril formation, and is localized to Abeta deposits in Alzheimer's disease brain. Mol Cell Neurosci. 2000 Feb;15(2):183-98. 
Mitolo et al.: Effects of Light Treatment in Patients with Alzheimer's Disease

15 Koronyo-Hamaoui M, Koronyo Y, Ljubimov AV, Miller CA, Ko MK, Black KL, et al. Identification of amyloid plaques in retinas from Alzheimer's patients and noninvasive in vivo optical imaging of retinal plaques in a mouse model. Neuroimage. 2011 Jan;54 Suppl 1:S204-17.

16 Ning A, Cui J, To E, Ashe KH, Matsubara J. Amyloid- $\beta$ deposits lead to retinal degeneration in a mouse model of Alzheimer disease. Invest Ophthalmol Vis Sci. 2008 Nov;49(11):5136-43.

17 Koronyo Y, Biggs D, Barron E, Boyer DS, Pearlman JA, Au WJ, et al: Retinal amyloid pathology and proof-ofconcept imaging trial in Alzheimer's disease. JCI Insight. 2017 Aug;2(16):pii: 93621.

18 La Morgia C, Ross-Cisneros FN, Koronyo Y, Hannibal J, Gallassi R, Cantalupo G, et al. Melanopsin retinal ganglion cell loss in Alzheimer disease. Ann Neurol. 2016 Jan;79(1):90-109.

19 Berson DM, Dunn FA, Takao M. Phototransduction by retinal ganglion cells that set the circadian clock. Science. 2002 Feb;295(5557):1070-3.

20 Hattar S, Liao HW, Takao M, Berson DM, Yau KW. Melanopsin-containing retinal ganglion cells: architecture, projections, and intrinsic photosensitivity. Science. 2002 Feb;295(5557):1065-70.

21 Hannibal J, Fahrenkrug J. Neuronal input pathways to the brain's biological clock and their functional significance. Adv Anat Embryol Cell Biol. 2006;182:1-71.

22 Sadun AA, Schaechter JD, Smith LE. A retinohypothalamic pathway in man: light mediation of circadian rhythms. Brain Res. 1984 Jun;302(2):371-7.

23 Feng R, Li L, Yu H, Liu M, Zhao W. Melanopsin retinal ganglion cell loss and circadian dysfunction in Alzheimer's disease (Review). Mol Med Rep. 2016 Apr;13(4):3397-400.

24 Saeed Y, Abbott SM. Circadian Disruption Associated with Alzheimer's Disease. Curr Neurol Neurosci Rep. 2017 Apr;17(4):29.

25 Haffmans PM, Sival RC, Lucius SA, Cats Q, van Gelder L. Bright light therapy and melatonin in motor restless behaviour in dementia: a placebo-controlled study. Int J Geriatr Psychiatry. 2001 Jan;16(1):106-10.

26 Mishima K, Tozawa T, Satoh K, Matsumoto Y, Hishikawa Y, Okawa M. Melatonin secretion rhythm disorders in patients with senile dementia of Alzheimer's type with disturbed sleep-waking. Biol Psychiatry. 1999 Feb; 45(4):417-21.

27 Satlin A, Volicer L, Ross V, Herz L, Campbell S. Bright light treatment of behavioral and sleep disturbances in patients with Alzheimer's disease. Am J Psychiatry. 1992 Aug;149(8):1028-32.

28 Forbes D, Culum I, Lischka AR, Morgan DG, Peacock S, Forbes J, et al. Light therapy for managing cognitive, sleep, functional, behavioural, or psychiatric disturbances in dementia. Cochrane Database Syst Rev. 2009 Oct;(4):CD003946.

29 Forbes D, Blake CM, Thiessen EJ, Peacock S, Hawranik P. Light therapy for improving cognition, activities of daily living, sleep, challenging behaviour, and psychiatric disturbances in dementia. Cochrane Database Syst Rev. 2014 Feb;(2):CD003946.

30 Millán-Calenti JC, Lorenzo-López L, Alonso-Búa B, de Labra C, González-Abraldes I, Maseda A. Optimal nonpharmacological management of agitation in Alzheimer's disease: challenges and solutions. Clin Interv Aging. 2016 Feb;11:175-84.

31 Salami O, Lyketsos C, Rao V. Treatment of sleep disturbance in Alzheimer's dementia. Int J Geriatr Psychiatry. 2011 Aug;26(8):771-82.

32 Richardson WS, Wilson MC, Nishikawa J, Hayward RS. The well-built clinical question: a key to evidence-based decisions. ACP J Club. 1995 Nov-Dec;123(3):A12-3.

33 U.S. Preventive Services Task Force. Guide to clinical preventive services: report of the U.S. Preventive Services Task Force. Collingdale: DIANE Publishing; 1989. p. 24.

34 Ancoli-Israel S, Gehrman P, Martin JL, Shochat T, Marler M, Corey-Bloom J, et al. Increased light exposure consolidates sleep and strengthens circadian rhythms in severe Alzheimer's disease patients. Behav Sleep Med. 2003a;1(1):22-36.

35 Ancoli-Israel S, Martin JL, Kripke DF, Marler M, Klauber MR. Effect of light treatment on sleep and circadian rhythms in demented nursing home patients. J Am Geriatr Soc. 2002 Feb;50(2):282-9.

36 Figueiro MG, Plitnick BA, Lok A, Jones GE, Higgins P, Hornick TR, et al. Tailored lighting intervention improves measures of sleep, depression, and agitation in persons with Alzheimer's disease and related dementia living in long-term care facilities. Clin Interv Aging. 2014 Sep; 9:1527-37.

37 Figueiro MG, Hunter CM, Higgins P, Hornick T, Jones GE, Plitnick B, et al. Tailored Lighting Intervention for Persons with Dementia and Caregivers Living at Home. Sleep Health. 2015 Dec;1(4):322-30.

38 Sloane PD, Figueiro M, Garg S, Cohen LW, Reed D, Williams CS, et al. Effect of home-based light treatment on persons with dementia and their caregivers. Light Res Technol. 2015 Apr;47(2):161-76.

39 Van Someren EJ, Kessler A, Mirmiran M, Swaab DF. Indirect bright light improves circadian rest-activity rhythm disturbances in demented patients. Biol Psychiatry. 1997 May;41(9):955-63.

40 Fontana Gasio P, Kräuchi K, Cajochen C, Someren E, Amrhein I, Pache M, et al. Dawn-dusk simulation light therapy of disturbed circadian rest-activity cycles in demented elderly. Exp Gerontol. 2003 Jan-Feb;38(1-2): 207-16.

41 Fetveit A, Skjerve A, Bjorvatn B. Bright light treatment improves sleep in institutionalised elderly-an open trial. Int J Geriatr Psychiatry. 2003 Jun;18(6):520-6.

42 Fetveit A, Bjorvatn B. Bright-light treatment reduces actigraphic-measured daytime sleep in nursing home patients with dementia: a pilot study. Am J Geriatr Psychiatry. 2005 May;13(5):420-3. 
43 Fetveit A, Bjorvatn B. The effects of bright-light therapy on actigraphical measured sleep last for several weeks post-treatment. A study in a nursing home population. J Sleep Res. 2004 Jun;13(2):153-8.

44 Dowling GA, Hubbard EM, Mastick J, Luxenberg JS, Burr RL, Van Someren EJ. Effect of morning bright light treatment for rest-activity disruption in institutionalized patients with severe Alzheimer's disease. Int Psychogeriatr. 2005a Jun;17(2):221-36.

45 Dowling GA, Mastick J, Hubbard EM, Luxenberg JS, Burr RL. Effect of timed bright light treatment for restactivity disruption in institutionalized patients with Alzheimer's disease. Int J Geriatr Psychiatry. 2005b Aug; 20(8):738-43.

46 Yamadera H, Ito T, Suzuki H, Asayama K, Ito R, Endo S. Effects of bright light on cognitive and sleep-wake (circadian) rhythm disturbances in Alzheimer-type dementia. Psychiatry Clin Neurosci. 2000 Jun;54(3): 352-3.

47 Skjerve A, Holsten F, Aarsland D, Bjorvatn B, Nygaard HA, Johansen IM. Improvement in behavioral symptoms and advance of activity acrophase after short-term bright light treatment in severe dementia. Psychiatry Clin Neurosci. 2004 Aug;58(4):343-7.

48 Burns A, Allen H, Tomenson B, Duignan D, Byrne J. Bright light therapy for agitation in dementia: a randomized controlled trial. Int Psychogeriatr. 2009 Aug;21(4):711-21.

49 Koyama E, Matsubara H, Nakano T. Bright light treatment for sleep-wake disturbances in aged individuals with dementia. Psychiatry Clin Neurosci. 1999 Apr;53(2):227-9.

50 Lyketsos CG, Lindell Veiel L, Baker A, Steele C. A randomized, controlled trial of bright light therapy for agitated behaviors in dementia patients residing in long-term care. Int J Geriatr Psychiatry. 1999 Jul;14(7):520-5.

51 Graf A, Wallner C, Schubert V, Willeit M, Wlk W, Fischer P, et al: The effects of light therapy on mini-mental state examination scores in demented patients. Biol Psychiatry. 2001 Nov;50(9):725-7.

52 Riemersma-van der Lek RF, Swaab DF, Twisk J, Hol EM, Hoogendijk WJ, Van Someren EJ. Effect of bright light and melatonin on cognitive and noncognitive function in elderly residents of group care facilities: a randomized controlled trial. JAMA. 2008 Jun;299(22):2642-55.

53 Lovell BB, Ancoli-Israel S, Gevirtz R. Effect of bright light treatment on agitated behavior in institutionalized elderly subjects. Psychiatry Res. 1995 Jun;57(1):7-12.

54 Mishima K, Okawa M, Hishikawa Y, Hozumi S, Hori H, Takahashi K. Morning bright light therapy for sleep and behavior disorders in elderly patients with dementia. Acta Psychiatr Scand. 1994 Jan;89(1):1-7.

55 Ancoli-Israel S, Martin JL, Gehrman P, Shochat T, Corey-Bloom J, Marler M, et al. Effect of light on agitation in institutionalized patients with severe Alzheimer disease. Am J Geriatr Psychiatry. 2003b Mar-Apr;11(2):194203.

56 Barrick AL, Sloane PD, Williams CS, Mitchell CM, Connell BR, Wood W, et al. Impact of ambient bright light on agitation in dementia. Int J Geriatr Psychiatry. 2010 Oct;25(10):1013-21.

57 Dowling GA, Graf CL, Hubbard EM, Luxenberg JS. Light treatment for neuropsychiatric behaviors in Alzheimer's disease. West J Nurs Res. 2007 Dec;29(8):961-75.

58 Onega LL, Pierce TW, Epperly L. Effect of Bright Light Exposure on Depression and Agitation in Older Adults with Dementia. Issues Ment Health Nurs. 2016 Sep;37(9):660-7.

59 Hickman SE, Barrick AL, Williams CS, Zimmerman S, Connell BR, Preisser JS, et al. The effect of ambient bright light therapy on depressive symptoms in persons with dementia. J Am Geriatr Soc. 2007 Nov;55(11):1817-24.

60 Schindler SD, Graf A, Fischer P, Tölk A, Kasper S. Paranoid delusions and hallucinations and bright light therapy in Alzheimer's disease. Int J Geriatr Psychiatry. 2002 Nov;17(11):1071-2.

61 Mishima K, Hishikawa Y, Okawa M. Randomized, dim light controlled, crossover test of morning bright light therapy for rest-activity rhythm disorders in patients with vascular dementia and dementia of Alzheimer's type. Chronobiol Int. 1998 Nov;15(6):647-54.

62 Sekiguchi H, Iritani S, Fujita K. Bright light therapy for sleep disturbance in dementia is most effective for mild to moderate Alzheimer's type dementia: a case series. Psychogeriatrics. 2017 Sep;17(5):275-81.

63 Dubois B, Hampel H, Feldman HH, Scheltens P, Aisen P, Andrieu S, et al.; Proceedings of the Meeting of the International Working Group (IWG) and the American Alzheimer's Association on "The Preclinical State of AD"; July 23, 2015; Washington DC, USA. Preclinical Alzheimer's disease: Definition, natural history, and diagnostic criteria. Alzheimers Dement. 2016 Mar;12(3):292-323.

64 Sloane PD, Williams CS, Mitchell CM, Preisser JS, Wood W, Barrick AL, et al. High-intensity environmental light in dementia: effect on sleep and activity. J Am Geriatr Soc. 2007 Oct;55(10):1524-33.

65 Most EI, Scheltens P, Van Someren EJ. Prevention of depression and sleep disturbances in elderly with memory-problems by activation of the biological clock with light—a randomized clinical trial. Trials. 2010 Feb;11(1):19.

66 Vandewalle G, Schmidt C, Albouy G, Sterpenich V, Darsaud A, Rauchs G, et al. Brain responses to violet, blue, and green monochromatic light exposures in humans: prominent role of blue light and the brainstem. PLoS One. 2007 Nov;2(11):e1247.

67 Oldham MA, Ciraulo DA. Bright light therapy for depression: a review of its effects on chronobiology and the autonomic nervous system. Chronobiol Int. 2014 Apr;31(3):305-19.

68 Al-Karawi D, Jubair L. Bright light therapy for nonseasonal depression: meta-analysis of clinical trials. J Affect Disord. 2016 Jul;198(198):64-71.

69 Beauchamp MT, Lundgren JD. A Systematic Review of Bright Light Therapy for Eating Disorders. Prim Care Companion CNS Disord. 2016 Oct;18(5). https://doi.org/10.4088/PCC.16r02008. 